\title{
Significance of Histological Crescent Formation in Patients with Diffuse Proliferative Lupus Nephritis
}

\author{
Shasha Chen Zheng Tang Yiyan Zhang Zhengzhao Liu Haitao Zhang \\ Weixin $\mathrm{Hu}$ Zhihong Liu \\ Research Institute of Nephrology, Jinling Hospital, Nanjing University School of Medicine, Nanjing, China
}

\author{
Key Words \\ Crescent · Diffuse proliferative lupus nephritis . \\ Clinicopathological features
}

\begin{abstract}
Background: Although crescentic nephritis is not rare in diffuse proliferative lupus nephritis (DPLN), little is known about the clinicopathological features in DPLN with crescents worldwide. This study was undertaken to investigate the clinicopathological features and outcome of Chinese DPLN patients with different degrees of crescents. Methods: 520 DPLN patients with more than $10 \%$ histological crescents (cDPLN) were enrolled in this retrospective study. They were divided into three groups: group $1(10 \% \leq$ crescents $<25 \%, \mathrm{n}=240)$, group $2(25 \% \leq$ crescents $<50 \%, \mathrm{n}=160)$, and group 3 (crescents $\geq 50 \%, n=120$ ). Another 100 patients without histological crescents were enrolled as a control group. Clinicopathological features, treatment responses, and outcomes were compared among the four groups. $\boldsymbol{R} \boldsymbol{e}$ sults: There were 450 (86.6\%) females and 70 (13.4\%) males with an average age of $31.7 \pm 11.4$ years. Compared with the control group, cDPLN patients had shorter lupus nephritis duration ( $20.7 \pm 34.1$ vs. $30.4 \pm 48.9$ months), higher prevalence of rapidly progressive glomerulonephritis syndrome (21.8\%), and gross hematuria (26.7\%). Laboratory findings indicated more severe hypoproteinemia, hyperlipidemia,
\end{abstract}

and renal insufficiency; heavier proteinuria and microscopic hematuria; higher tubular injury parameters, and lower serological activity in crescentic groups. Histologically, cDPLN patients have severe glomerular and tubulointerstitial lesions as well as extensive leukocyte infiltration together with a lesser degree of immune complex deposition. The proportion of death, end-stage renal disease, and treatment failure correlates positively with the degree of histological crescents. Conclusions: cDPLN patients with acute onset and short disease duration mostly show severe renal manifestations, less extrarenal organ involvement, lower serological activity, serious capillary necrosis, severe tubulointerstitial inflammation, atrophy and fibrosis, prominent leukocyte infiltration, less glomerular immune complex deposition, poor treatment response, and worse renal outcome.

(c) 2013 S. Karger AG, Basel

\section{Introduction}

It has been reported that lupus nephritis $(\mathrm{LN})$ is the commonest secondary disease of crescentic glomerulonephritis [1], occurring in 33.9\% of crescentic glomerulonephritis, and $54.6 \%$ of type II (immune-complex) crescentic glomerulonephritis in Chinese patients [2, 3]. Crescentic nephritis is not rare in LN, especially in diffuse proliferative lupus nephritis (DPLN). While DPLN itself

\section{KARGER}

E-Mail karger@karger.com

www.karger.com/ajn
(C) 2013 S. Karger AG, Basel

0250-8095/13/0386-0445\$38.00/0 
Table 1. Demographic characteristics

\begin{tabular}{lllll}
\hline & Control & $\begin{array}{l}\text { Group 1 }(10 \% \leq \\
\text { crescents }<25 \%)\end{array}$ & $\begin{array}{l}\text { Group 2 (25\% } \\
\text { crescents <50\%) }\end{array}$ & $\begin{array}{l}\text { Group 3 } \\
(\text { crescents } \geq 50 \%)\end{array}$ \\
\hline Patients, $n$ & 100 & 240 & 160 & 120 \\
Age, years & $32.1 \pm 11.9$ & $33.3 \pm 11.4^{\mathrm{a}, \mathrm{b}}$ & $30.9 \pm 11.2$ & $30.1 \pm 10.9$ \\
Onset age, years & $28.7 \pm 10.9$ & $29.8 \pm 11.3$ & $28.7 \pm 11.1$ & $27.3 \pm 10.5$ \\
Females, n & 84.0 & 86.3 & 88.2 & 85.0 \\
Duration of SLE, months & $39.6 \pm 51.9$ & $41.5 \pm 48.6^{\mathrm{a}}$ & $27.1 \pm 38.8$ & $29.7 \pm 36.7$ \\
Duration of LN, months & $30.4 \pm 48.9^{\text {c, d }}$ & $29.6 \pm 43.8^{\mathrm{a}, \mathrm{b}}$ & $14.4 \pm 23.9$ & $15.5 \pm 24.7$ \\
\hline
\end{tabular}

${ }^{\mathrm{a}} \mathrm{p}<0.05$ between group 1 and group $2 .{ }^{\mathrm{b}} \mathrm{p}<0.05$ between group 1 and group $3 .{ }^{\mathrm{c}} \mathrm{p}<0.05$ between control and group $2 .{ }^{\mathrm{d}} \mathrm{p}<0.05$ between control and group 3 .

carries a poor prognosis if timely intervention is not carried out [4], the formation of crescents further warrants rapid deterioration of renal function and a very poor outcome $[5,6]$. Despite considerable improvements in the treatment of crescentic LN in recent years, $25-30 \%$ of patients will develop end-stage renal disease (ESRD), necessitating lifelong renal replacement therapy [7]. Therefore, early diagnosis and proactive intervention should be emphasized in these patients. However, there are limited detailed reports currently available concerning demographic, clinical, and pathological features in lupus patients with various degrees of histological crescents except for a few reports on DPLN patients with more than 50\% glomeruli having crescents on light microscopy [8-10]. In this study, we conducted a retrospective analysis of a biopsyproven cohort of 520 patients with more than $10 \%$ crescents in DPLN, which may shed some new light on further pathogenic and therapeutic studies.

\section{Methods}

\section{Patients}

The clinicopathological characteristics of 520 biopsy-proven DPLN patients with more than $10 \%$ crescents (cDPLN) diagnosed between 2000 and 2010 in Nanjing Jinling Hospital were retrospectively reviewed. The inclusion criteria were: (1) diagnosed as systemic lupus erythematosus (SLE) as defined by the 1997 revised American Rheumatism Association criteria [11], (2) renal biopsy-confirmed DPLN according to the 2003 International Society of Nephrology/Renal Pathology Society classification [12], and (3) at least $10 \%$ of the glomeruli having crescents ('extracapillary cells more than two layers thick involving $\geq 25 \%$ of the glomerular circumference'). Reasons for exclusion were: (1) $<10$ nonsclerotic glomeruli in sampled renal tissue, (2) biopsy aged $<18$ years, (3) class IV LN mixed with other histological types such as IV+V or IV+III, and (4) life-threatening complications such as pancreatitis, gastrointestinal hemorrhage, se- vere infection, severe cardiovascular disease, and bone marrow insufficiency. According to the degree of histological crescents, the cDPLN patients were divided into three subgroups: group 1 $(10 \% \leq$ crescents $<25 \%, \mathrm{n}=240)$, group $2(25 \% \leq$ crescents $<50 \%$, $\mathrm{n}=160$ ), and group 3 (crescents $\geq 50 \%, \mathrm{n}=120$ ). Another 100 DPLN patients without crescent formation were regarded as a control group. The clinicopathological features, treatment response and renal function deterioration were compared among the four groups.

\section{Renal Pathology}

Percutaneous renal biopsy was carried out under ultrasound guidance. DPLN was defined as $>50 \%$ of glomeruli on light microscopy having segmental or global endocapillary or extracapillary glomerulonephritis as well as mesangial involvement [12]. Pathological parameters such as activity indexes (AI) and chronic indexes (CI) were approached by renal pathologists using a modification of an earlier reported system involving semiquantitative scoring of specific biopsy features [13]. Tubulointerstitial lesions including tubular atrophy and interstitial fibrosis as well as interstitial inflammation were semiquantitatively graded as none (0), mild (1), moderate (2), or severe (3) [14]. Immunofluorescence for deposition of IgG, IgA, IgM, C3, C1q, and fibrin deposits was semiquantitatively graded from 0 to $4+$ according to the intensity of fluorescence.

\section{Definitions}

Complete remission was defined as urinary protein excretion $<0.3 \mathrm{~g} /$ day, normal urinary sediment, and normal or stable renal function (within $10 \%$ of normal eGFR if previously abnormal renal function). Partial remission was defined as a urinary protein excretion within the range of $0.3-2.9 \mathrm{~g} /$ day with a stable or improved renal function [15]. Treatment failure was defined as a sustained $25 \%$ increase in serum creatinine, an increase in proteinuria, or a reduction in proteinuria but not to the extent of complete or partial remission. A relapse was defined as persistent increase in proteinuria $>1 \mathrm{~g}$ /day after complete remission or a doubling of proteinuria with values $>2 \mathrm{~g}$ /day after achieving partial remission, or recurrence of active urinary sediment and/or an increase of $\geq 25 \%$ in serum creatinine [16]. ESRD was defined as a serum creatinine $>6 \mathrm{mg} / \mathrm{dl}(>528 \mathrm{mmol} / \mathrm{l})$, or the initiation of renal replacement therapy [17]. 
Table 2. Clinical and laboratory features of renal damage

\begin{tabular}{|c|c|c|c|c|}
\hline & Control & $\begin{array}{l}\text { Group } 1(10 \% \leq \\
\text { crescents }<25 \%)\end{array}$ & $\begin{array}{l}\text { Group } 2(25 \% \leq \\
\text { crescents }<50 \%)\end{array}$ & $\begin{array}{l}\text { Group } 3 \\
\text { (crescents } \geq 50 \% \text { ) }\end{array}$ \\
\hline $\mathrm{UAB}, \%$ & 46.6 & 33.5 & 19.4 & 20.8 \\
\hline NS, \% & 19.4 & 28.2 & 23.5 & 15.8 \\
\hline RPGN, \% & 1 & 6.4 & 24.1 & 42.5 \\
\hline CRF, \% & 6.8 & 10.6 & 9.4 & 1.7 \\
\hline Gross hematuria, \% & 12.3 & 22.6 & 27.6 & 31.7 \\
\hline BUN, mg/dl & $25.9 \pm 17.1^{\mathrm{a}-\mathrm{c}}$ & $32.5 \pm 21.1$ & $35.4 \pm 28.2$ & $39.6 \pm 24.1$ \\
\hline $\mathrm{SCr}, \mathrm{mg} / \mathrm{dl}$ & $1.3 \pm 2.0^{\mathrm{b}, \mathrm{c}}$ & $1.5 \pm 1.4^{\mathrm{d}, \mathrm{e}}$ & $2.0 \pm 2.0$ & $2.4 \pm 2.2$ \\
\hline Urine protein, g/day & $3.0 \pm 2.9^{b, c}$ & $3.6 \pm 2.9^{\mathrm{e}}$ & $4.4 \pm 3.3$ & $4.8 \pm 3.3$ \\
\hline Urinary sediment, $\times 10^{4} / \mathrm{ml}$ & $307.8 \pm 822.7$ & $700.5 \pm 2,846.1$ & $524.1 \pm 1,018.4$ & $784.0 \pm 1,794.0$ \\
\hline Urinary C3, mg/l & $4.3 \pm 4.6^{\mathrm{a}-\mathrm{c}}$ & $8.5 \pm 0.6^{\mathrm{e}}$ & $11.1 \pm 1.0$ & $12.8 \pm 1.4$ \\
\hline $\mathrm{NAG}, \mathrm{U} / \mathrm{g} \cdot \mathrm{Cr}$ & $46.6 \pm 35.9^{a-c}$ & $58.9 \pm 41.0^{\mathrm{e}}$ & $70.7 \pm 46.9$ & $74.9 \pm 46.0$ \\
\hline $\mathrm{RBP}, \mathrm{mg} / \mathrm{l}$ & $3.0 \pm 5.2^{\mathrm{a}-\mathrm{c}}$ & $6.0 \pm 11.4^{\mathrm{e}}$ & $9.9 \pm 19.5$ & $11.7 \pm 17.4$ \\
\hline
\end{tabular}

$\mathrm{UAB}=$ Abnormal urinalysis; $\mathrm{NS}$ = nephrotic syndrome; RPGN = rapidly progressive glomerulonephritis syndrome; RBP = retinol-binding protein. ${ }^{\mathrm{a}} \mathrm{p}<0.05$ between control and group $1 .{ }^{\mathrm{b}} \mathrm{p}<0.05$ between control and group $2 .{ }^{\mathrm{c}} \mathrm{p}<0.05$ between control and group $3 .{ }^{\mathrm{d}} \mathrm{p}<0.05$ between group 1 and group $2 .{ }^{\mathrm{e}} \mathrm{p}<0.05$ between group 1 and group 3 .

Statistical Analysis

All data were analyzed by using statistical software SPSS 19.0. Quantitative data were expressed as means \pm SD. All parameters were compared by a $\chi^{2}$ test or Fisher's exact test for categorical data, and Student's t test or a one-way analysis of variance for continuous data. A Spearman test was used for correlation analysis. Statistical significance was considered as $\mathrm{p}<0.05$.

\section{Results}

\section{General Condition}

There were 450 (86.6\%) females and $70(13.4 \%)$ males with an average age and onset age of $31.6 \pm 11.3$ and 28.8 \pm 11.1 years, respectively. The duration of SLE and LN were $34.5 \pm 42.9$ and $20.7 \pm 34.1$ months, respectively. Group 1 showed a higher average age and disease-onset age than the other groups (table 1).

\section{Clinical and Laboratory Features of Renal Damage}

As shown in table 2, cDPLN patients more frequently manifested with rapidly progressive glomerulonephritis syndrome $(21.8 \%)$, gross hematuria $(26.7 \%)$, nephrotic syndrome (23.4\%), and chronic renal failure (CRF; 7.9\%). Their average levels of urea nitrogen and creatinine at renal biopsy were $35.3 \pm 23.6$ versus $25.8 \pm 17.1 \mathrm{mg} / \mathrm{dl}$ and $1.9 \pm 1.9$ versus $1.2 \pm 1.9 \mathrm{mg} / \mathrm{dl}$, respectively, compared with the control group. Groups 1 and 2 had a higher proportion of CRF than the control group $(\mathrm{p}=0.261, \mathrm{p}=$
0.412), and group 3 had a lower proportion of CRF than the control group $(\mathrm{p}=0.12)$. A positive correlation existed among the levels of urea nitrogen $(p<0.01)$, creatinine $(\mathrm{p}<0.01)$, proteinuria $(\mathrm{p}<0.001)$, NAG (n-acetyl$\beta$-D-glucosaminidase; $\mathrm{p}<0.001)$, retinol-binding protein $(\mathrm{p}<0.001)$, and urine C3 with the degree of crescents (table 2).

\section{Immunological Characteristics}

In the $520 \mathrm{cDPLN}$ patients, the rates of positive ANA, ds-DNA, Sm, RNP, SSA, SSB, ACL, LA, and ANCA were $98.3,68.8,21.7,27.1,50.9,13.4,29.9,2.6$, and $3.1 \%$, respectively. A negative correlation of albumin $(\mathrm{p}<0.001)$ and rate of positive RNP $(\mathrm{p}<0.001)$ was found with the crescent ratio among the four groups, while the rate of positive LA $(\mathrm{p}<0001)$ and ANCA $(\mathrm{p}=0.071)$ increased with the rising ratio of crescents. Lower values of globulin $(\mathrm{p}<0.001)$, cryoglobulin $(\mathrm{p}=0.376), \operatorname{IgG}(\mathrm{p}=0.001)$, ANA $(\mathrm{p}=0.08)$, and ds-DNA titers $(\mathrm{p}=0.64)$, a lower ratio of positive Sm $(\mathrm{p}=0.003)$ and ACL $(\mathrm{p}<0001)$, and higher levels of $\mathrm{C} 3(\mathrm{p}=0.022)$ and $\mathrm{C} 4(\mathrm{p}=0.004)$ were observed in the cDPLN groups (table 3 ).

\section{Renal Pathological Characteristics}

The mean scores of AI and CI in cDPLN patients compared with the control group were $10.6 \pm 4.1$ versus $6.7 \pm$ 3.4 and $2.3 \pm 1.9$ versus $1.7 \pm 2.1$. In cDPLN patients, besides cellular $(\mathrm{p}<0.001)$, fibrocellular $(\mathrm{p}<0.001)$, and 
Table 3. Immunological characteristics

\begin{tabular}{lcccc}
\hline & Control & $\begin{array}{c}\text { Group 1 }(10 \% \leq \\
\text { crescents }<25 \%)\end{array}$ & $\begin{array}{c}\text { Group 2 }(25 \% \leq \\
\text { crescents }<50 \%)\end{array}$ & $\begin{array}{l}\text { Group 3 } \\
\text { (crescents } \geq 50 \%)\end{array}$ \\
\hline Alb, g/l & $29.5 \pm 7.2^{\mathrm{a}, \mathrm{b}}$ & $27.9 \pm 7.0^{\mathrm{c}, \mathrm{d}}$ & $25.8 \pm 5.7$ & $24.7 \pm 5.9$ \\
Glo, g/l & $26.8 \pm 7.9^{\mathrm{a}, \mathrm{b}, \mathrm{e}}$ & $23.5 \pm 6.5$ & $24.0 \pm 7.2$ & $23.3 \pm 6.5$ \\
CG, mg/l & $380.6 \pm 297.7$ & $322.3 \pm 192.7$ & $316.5 \pm 238.2$ & $329.2 \pm 353.8$ \\
IgG, g/l & $13.9 \pm 9.2^{\mathrm{a}, \mathrm{b}, \mathrm{e}}$ & $10.4 \pm 5.6$ & $10.5 \pm 6.7$ & $10.4 \pm 5.7$ \\
ANA (1:n) & $654.3 \pm 581.4^{\mathrm{a}, \mathrm{e}}$ & $524.5 \pm 528.8$ & $480.3 \pm 540.3$ & $537.7 \pm 543.3$ \\
ds-DNA (1:n) & $25.7 \pm 33.1$ & $19.1 \pm 32.8$ & $25.7 \pm 85.4$ & $24.4 \pm 42.6$ \\
Positive ACL, $\%$ & 48.1 & 36.7 & 23.5 & 28.3 \\
Positive LA, \% & 0.9 & 0.5 & 8.3 & 17.6 \\
Positive ANCA, $\%$ & 0 & 2.2 & 2.3 & 5.8 \\
C3, g/l & $0.434 \pm 0.248^{\mathrm{b}}$ & $0.499 \pm 0.245$ & $0.494 \pm 0.225$ & $0.545 \pm 0.356$ \\
C4, g/l & $0.106 \pm 0.126$ & $0.118 \pm 0.089$ & $0.135 \pm 0.107$ & $0.159 \pm 0.163$ \\
\hline
\end{tabular}

${ }^{\mathrm{a}} \mathrm{p}<0.05$ between the control group and group $2 .{ }^{\mathrm{b}} \mathrm{p}<0.05$ between the control group and group $3 .{ }^{\mathrm{c}} \mathrm{p}<0.05$ between group 1 and group 2. ${ }^{\mathrm{d}} \mathrm{p}<0.05$ between group 1 and group $3 .{ }^{\mathrm{e}} \mathrm{p}<0.05$ between the control group and group 1.

fibrous crescents $(p<0.001)$, the percentage of cases with capillary necrosis $(p<0.001)$, score of interstitial inflammation ( $\mathrm{p}<0.001)$, and AI ( $<<0.001)$ increased along with the rising ratio of crescents. The scores of acute tubulointerstitial lesions $(\mathrm{p}=0.103)$ and chronic tubulointerstitial lesions $(\mathrm{p}<0.001)$ were higher in the cDPLN groups than in the control group. Group 1 had the most severe acute tubulointerstitial lesions $(\mathrm{p}=0.113)$ and the highest ratio of glomerular sclerosis $(\mathrm{p}=0.186)$.

Immunofluorescence indicated that the average peripheral capillary loop intensity of $\operatorname{IgG}$, IgA, IgM, C3, and $\mathrm{C} 1 \mathrm{q}$ deposition was lower in CDPLN patients than those in the control group, and the differences in IgG, IgA, and IgM reached statistical significance $(\mathrm{p}<0.001, \mathrm{p}<0.001$, and $\mathrm{p}=0.008$, respectively; table 4 ).

\section{Renal Infiltrating Cells Analysis}

cDPLN patients, especially in group 3, had significantly higher numbers of infiltrating CD4 and CD8+ T cells in the renal interstitium than the control group. Interstitium infiltrating CD68+ T cells increased in proportion to the degree of histological crescents $(p<0.01$; table 5$)$.

\section{Extrarenal Manifestations}

The average SLE Disease Activity (SLE-DAI) score $[18,19]$ of cDPLN patients was $15.2 \pm 5.7$. The main extrarenal manifestation included arthritis (54.6\%), hypertension (51.3\%), anemia (49.4\%), and malar rash (46.5\%). The ratio of hypertension $(\mathrm{p}<0.001)$ and anemia $(\mathrm{p}<$
0.001 ) were in positive proportion to the percentage of crescents. A higher SLE-DAI score $(p=0.021)$, higher proportion of serositis $(\mathrm{p}=0.043)$, malignant hypertension ( $\mathrm{p}=0.510)$, and TTP/HUS $(\mathrm{p}=0.057)$ were observed in the cDPLN groups than those in the control group, but not completely proportional to the ratio of crescent in total glomeruli. Group 1 exhibited the highest ratio of malignant hypertension $(\mathrm{p}<0.01)$, TTP/HUS $(\mathrm{p}=0.094)$, and malar rash $(\mathrm{p}=0.069)$ (data not shown).

\section{Follow-Up}

A total of 620 DPLN patients were treated with a flexible strategy, mainly based on high-dose corticosteroids and cytotoxic agents for induction and maintenance after biopsy. There was no significant difference in the treatment algorithm among the four groups. The follow-up time ranged from 1 month to 10 years. In the cDPLN groups, 28 patients $(5.6 \%)$ died of renal disease, 32 patients (6.1\%) reached ESRD, 101 patients (19.4\%) developed CRF, and 357 patients (68.7\%) maintained normal renal function. The proportion of death and ESRD correlated positively with the degree of histological crescents. Excluding those with serum creatinine exceeding $4.5 \mathrm{mg} /$ $\mathrm{dl}$ or followed for less than 60 months, it was found that 320 cDPLN patients had a lower complete remission rate after longer time of treatment. It was found that the higher the percentage of histological crescents, the lower the proportion of patients showing a good response to immune-suppressive therapy during follow-up (table 6). 
Table 4. Renal pathological characteristics

\begin{tabular}{|c|c|c|c|c|}
\hline & Control & $\begin{array}{l}\text { Group } 1(10 \% \leq \\
\text { crescents }<25 \%)\end{array}$ & $\begin{array}{l}\text { Group } 2(25 \% \leq \\
\text { crescents }<50 \%)\end{array}$ & $\begin{array}{l}\text { Group } 3 \\
\text { (crescents } \geq 50 \% \text { ) }\end{array}$ \\
\hline Glomeruli, n & $26.7 \pm 10.3^{b, c}$ & $26.1 \pm 11.7^{\mathrm{d}, \mathrm{e}}$ & $22.9 \pm 8.7$ & $21.7 \pm 9.5$ \\
\hline \multicolumn{5}{|l|}{ Light microscope } \\
\hline Glomerular sclerosis, \% & $7.8 \pm 14.2$ & $9.0 \pm 15.6^{\mathrm{e}}$ & $7.1 \pm 12.0$ & $5.7 \pm 10.1$ \\
\hline Segmental sclerosis, \% & $1.8 \pm 7.9$ & $0.9 \pm 3.2$ & $1.1 \pm 5.0$ & $0.7 \pm 4.9$ \\
\hline Crescents, \% & $0^{\mathrm{a}-\mathrm{c}}$ & $19.0 \pm 6.0^{\mathrm{d}, \mathrm{e}}$ & $37.2 \pm 5.2^{\mathrm{f}}$ & $64.5 \pm 14.0$ \\
\hline Cellular crescents, $\%$ & $0^{\mathrm{a}-\mathrm{c}}$ & $8.0 \pm 8.4^{\mathrm{d}, \mathrm{e}}$ & $13.35 \pm 15.4^{\mathrm{f}}$ & $21.72 \pm 25.0$ \\
\hline Fibrocellular crescents, $\%$ & $0^{\mathrm{a}-\mathrm{c}}$ & $10.2 \pm 8.4^{\mathrm{d}, \mathrm{e}}$ & $20.5 \pm 16.1^{\mathrm{f}}$ & $39.2 \pm 25.4$ \\
\hline Fibrous crescents, $\%$ & $0^{\mathrm{a}-\mathrm{c}}$ & $0.9 \pm 3.5^{\mathrm{d}, \mathrm{e}}$ & $3.3 \pm 9.0^{\mathrm{f}}$ & $5.4 \pm 13.7$ \\
\hline Capillary necrosis, \% & 19.8 & 33.3 & 48.2 & 59.2 \\
\hline Wire loops, \% & 44.3 & 41.3 & 25.3 & 25.8 \\
\hline Capillary microthrombi, \% & 31.1 & 27.5 & 24.7 & 28.3 \\
\hline Acute tubulointerstitial lesion & $0.7 \pm 0.7^{\mathrm{a}}$ & $1.0 \pm 0.7^{\mathrm{e}}$ & $0.8 \pm 0.8$ & $0.8 \pm 0.8$ \\
\hline Chronic tubulointerstitial lesion & $0.5 \pm 0.7^{\mathrm{a}-\mathrm{c}}$ & $0.9 \pm 0.9$ & $0.9 \pm 0.9$ & $0.8 \pm 0.9$ \\
\hline Interstitial inflammation & $0.9 \pm 0.4^{\mathrm{a}-\mathrm{c}}$ & $1.0 \pm 0.5^{\mathrm{d}, \mathrm{e}}$ & $1.2 \pm 0.6^{\mathrm{f}}$ & $1.3 \pm 0.7$ \\
\hline \multicolumn{5}{|l|}{ Immunofluorescence } \\
\hline $\operatorname{IgG}$ & $2.0 \pm 0.2^{\mathrm{a}-\mathrm{c}}$ & $1.8 \pm 0.4^{\mathrm{d}}$ & $1.6 \pm 0.7$ & $1.7 \pm 0.6$ \\
\hline $\operatorname{IgA}$ & $1.5 \pm 0.6^{\mathrm{a}-\mathrm{c}}$ & $1.3 \pm 0.5$ & $1.1 \pm 0.5$ & $1.2 \pm 0.5$ \\
\hline $\operatorname{IgM}$ & $1.4 \pm 0.5^{\mathrm{a}, \mathrm{b}}$ & $1.2 \pm 0.4$ & $1.2 \pm 0.5$ & $1.2 \pm 0.5$ \\
\hline $\mathrm{C} 3$ & $2.0 \pm 0.3$ & $1.91 \pm 0.40$ & $1.9 \pm 0.6$ & $1.9 \pm 0.5$ \\
\hline $\mathrm{C} 4$ & $1.1 \pm 0.8$ & $0.98 \pm 0.7^{\mathrm{d}, \mathrm{e}}$ & $1.2 \pm 0.6$ & $1.4 \pm 0.61$ \\
\hline $\mathrm{C} 1 \mathrm{q}$ & $1.5 \pm 0.5$ & $1.5 \pm 0.5$ & $1.4 \pm 0.6$ & $1.5 \pm 0.5$ \\
\hline AI score & $6.7 \pm 3.3^{\mathrm{a}-\mathrm{c}}$ & $9.1 \pm 3.4^{\mathrm{e}}$ & $9.9 \pm 4.1^{\mathrm{f}}$ & $11.6 \pm 4.7$ \\
\hline CI score & $1.70 \pm 2.13^{a-c}$ & $2.27 \pm 1.78$ & $2.20 \pm 2.01$ & $2.33 \pm 2.00$ \\
\hline
\end{tabular}

${ }^{\mathrm{a}} \mathrm{p}<0.05$ between control and group $1 .{ }^{\mathrm{b}} \mathrm{p}<0.05$ between control and group $2 .{ }^{\mathrm{c}} \mathrm{p}<0.05$ between control and group $3 .{ }^{\mathrm{d}} \mathrm{p}<0.05$ between group 1 and group $2 .{ }^{\mathrm{e}} \mathrm{p}<0.05$ between group 1 and group $3 .{ }^{\mathrm{f}} \mathrm{p}<0.05$ between group 2 and group 3 .

Table 5. Renal infiltrating cells analysis

\begin{tabular}{|c|c|c|c|c|}
\hline & Control & $\begin{array}{l}\text { Group } 1(10 \% \leq \\
\text { crescents }<25 \%)\end{array}$ & $\begin{array}{l}\text { Group } 2(25 \% \leq \\
\text { crescents }<50 \%)\end{array}$ & $\begin{array}{l}\text { Group } 3 \\
\text { (crescents } \geq 50 \% \text { ) }\end{array}$ \\
\hline $\mathrm{CD} 4+$ in interstitium $\left(/ \mathrm{mm}^{2}\right)$ & $119.3 \pm 79.8^{\mathrm{a}-\mathrm{c}}$ & $170.2 \pm 133.9$ & $165.4 \pm 86.3$ & $184.9 \pm 111.6$ \\
\hline $\mathrm{CD} 8+$ in interstitium $\left(/ \mathrm{mm}^{2}\right)$ & $116.3 \pm 80.2^{\mathrm{a}-\mathrm{c}}$ & $177.8 \pm 124.3$ & $177.9 \pm 80.5$ & $197.7 \pm 113.6$ \\
\hline CD68+ in glomeruli (/glo) & $17.9 \pm 16.5$ & $17.6 \pm 31.5$ & $22.3 \pm 58.8$ & $12.9 \pm 10.5$ \\
\hline $\mathrm{CD} 68+$ in interstitium $\left(/ \mathrm{mm}^{2}\right)$ & $238.3 \pm 211.2^{\mathrm{a}-\mathrm{c}}$ & $391.5 \pm 271.6$ & $443.8 \pm 301.3$ & $496.4 \pm 424.0$ \\
\hline
\end{tabular}

${ }^{\mathrm{a}} \mathrm{p}<0.05$ between control and group $1 .{ }^{\mathrm{b}} \mathrm{p}<0.05$ between control and group $2 .{ }^{\mathrm{c}} \mathrm{p}<0.05$ between control and group 3 .

\section{Discussion}

We have previously analyzed data from Chinese patients with crescentic nephritis in our center to characterize the clinical spectrum of crescentic glomerulonephritis. $\mathrm{LN}$ was demonstrated to be the commonest cause of secondary disease of crescentic glomerulonephritis in Chinese patients, occurring in $33.9 \%$ of crescentic nephritis cases and $54.6 \%$ of type II (immune-complex) crescentic glomerulonephritis cases [2,3]. Crescents were considered a critical factor in the histologic classification for Henoch-Schönlein purpura nephritis as they signifi- 
Table 6. Treatment response and outcome

\begin{tabular}{|c|c|c|c|c|}
\hline & Control & $\begin{array}{l}\text { Group } 1(10 \% \leq \\
\text { crescents }<25 \%)\end{array}$ & $\begin{array}{l}\text { Group } 2(25 \% \leq \\
\text { crescents }<50 \%)\end{array}$ & $\begin{array}{l}\text { Group } 3 \\
\text { (crescents } \geq 50 \% \text { ) }\end{array}$ \\
\hline \multicolumn{5}{|l|}{ Induction treatment, $\%$} \\
\hline $\mathrm{MMF}+\mathrm{FK} 506$ + P & 27.3 & 22.2 & 12.7 & 16.7 \\
\hline MMF & 29.5 & 28.5 & 40.2 & 28.8 \\
\hline FK506 & 0 & 4.2 & 5.9 & 4.5 \\
\hline CTX & 28.4 & 39.6 & 24.5 & 39.4 \\
\hline \multicolumn{5}{|c|}{ Maintenance treatment, \% } \\
\hline $\mathrm{MMF}+\mathrm{FK} 506$ + P & 9.3 & 9.2 & 4.0 & 12.7 \\
\hline MMF & 26.7 & 20.6 & 29.3 & 22.2 \\
\hline FK506 & 0 & 0.7 & 0 & 0 \\
\hline CTX & 0 & 2.7 & 0 & 3.2 \\
\hline \multicolumn{5}{|l|}{ Treatment response, \% } \\
\hline $\mathrm{CR}$ & 78.3 & 66.7 & 61.8 & 74.2 \\
\hline 1-year & 40 & 47.9 & 52 & 54.5 \\
\hline 2-year & 73 & 62.5 & 56.9 & 62.1 \\
\hline 3-year & 74.8 & 66.7 & 59.8 & 68.2 \\
\hline $\mathrm{PR}$ & 18.3 & 25 & 29.4 & 15.2 \\
\hline $\mathrm{TF}$ & 3.5 & 8.3 & 8.8 & 10.6 \\
\hline Relapse rate & 37.8 & 41.7 & 49.5 & 31.7 \\
\hline \multicolumn{5}{|l|}{ Outcome, $n(\%)$} \\
\hline Death & $1(1.1)$ & $5(1.9)$ & $10(6.4)$ & $13(11.2)$ \\
\hline ESRD & $2(2.2)$ & $10(4.3)$ & $10(6.4)$ & $12(10.2)$ \\
\hline $\mathrm{CRF}$ & $13(13.2)$ & $45(18.6)$ & $29(18.4)$ & $27(22.4)$ \\
\hline Normal renal function & $83(83.5)$ & $180(75.2)$ & $110(68.8)$ & $67(56.1)$ \\
\hline
\end{tabular}

$\mathrm{CR}=$ Complete remission; $\mathrm{PR}=$ partial remission; $\mathrm{TF}=$ treatment failure.

cantly affect symptomatology and long-term outcome of the disease [20]; likewise, crescents may be helpful to define the severity of renal disease, guide the choice of treatment, and predict the prognosis of patients with crescentic LN.

The present study showed that DPLN was the major pathological type of LN with histological crescent formation, affecting $44.9 \%$ of initial biopsies with more than $10 \%$ of sampled glomeruli. cDPLN more frequently manifested with rapidly progressive glomerulonephritis syndrome, CRF, and gross hematuria than those without crescents, which is consistent with our earlier study [8]. Group 3 developed the lowest rate of CRF as this group mostly presented with acute onset, rapid progression, and severe symptoms such as gross hematuria, oliguria, and hypertension. Therefore, the time between presentation of LN and biopsy/treatment was usually shorter than for other groups, and this group mostly received timely nephrologist consultation as well as early and intensive intervention.
Similar to findings from another report which showed that DPLN patients with more than $50 \%$ crescents had a more serious laboratory and pathological presentation [9], our study indicated that DPLN patients with more than $10 \%$ histological crescents had more severe hypoproteinemia, hyperlipidemia, and renal insufficiency, heavier proteinuria and hematuria, and higher levels of tubular injury parameters. Immunologically, lower serological activity and a higher rate of positive LA and ANCA were observed in these patients. On pathologic evaluation, apart from the proportion of cellular crescents, fibrocellular and fibrous crescents, significantly higher scores of AI, CI, interstitial inflammation activity indexes, acute and chronic tubulointerstitial lesion activity indexes, as well as a higher rate of capillary necrosis, were identified in cDPLN patients than in those without crescents.

There is evidence supporting the notion that there are at least two mechanisms leading to glomerular damage in severe proliferative LN: a pauci-immune-mediated 
process leading to the damage occurring in segmental lesions, and a peripheral capillary wall immune aggregatemediated process in global lesions [21-28]. These reports have raised the possibility of a mechanism akin to pauciimmune necrotizing vasculitis for necrotizing and crescentic LN. Our results expand on these earlier observations in a large cohort of DPLN patients with extensive crescent formation with detailed clinical, laboratory, histology, and prognosis data. The percentage of capillary necrosis and positive ANCA correlated perfectly with the ratio of histological crescents. Besides, a lower ratio of hypocomplementemia, positive Sm, ACL, lower levels of ANA, ds-DNA, cryoglobulin, IgG, and serum CD20+ cells were observed in cDPLN patients. Moreover, less subendothelial 'wire loop' deposits, capillary microthrombi, and a lower intensity of peripheral capillary IgG, IgA, IgM, C3, and C1q deposition in cDPLN patients were observed. Though cell-mediated immunity plays a key role in crescent formation, with the increasing rate of crescent and uremia state, the humoral immunity response may be relatively suppressed, which could be proven by decreasing levels of complement, immunoglobulin, cryoglobulins, and CD20+ cells, thus resulting in less mature B cells and less production of autoantibodies, as well as less immune complex deposit in renal tissues. Our results, therefore, favor the interpretation that DPLN with crescents appears to be the result of two distinct pathogenetic mechanisms.

Glomerular crescents are a histopathologic marker of severe renal injury, characterized by disruption in the integrity of the glomerular capillary wall, leading to macrophage and $\mathrm{T}$ cell infiltration into the Bowman space, and further exacerbate the inflammatory process and glomerular injury [29]. We have previously demonstrated that monocytes (CD68+ cells) and T cells play a dominant role in the formation of crescents and contribute to the development of diffuse crescentic glomerulonephritis $[1,30]$. T cells could initiate autoimmunity, antigen recognition, and macrophage recruitment and activation. These macrophages subsequently release proinflammatory cytokines which result in cell proliferation, recruitment of more macrophages, and upregulation of adhesion molecule expression $[31,32]$. In this study, higher infiltrating numbers of CD4+, CD8+, and CD68+ cells were observed in renal tissues of crescentic glomerulonephritis compared with that in controls, and these may serve as useful markers for the active lesions in patients with crescentic DPLN.

It is generally assumed that a greater percentage of crescent formation in glomeruli will lead to the identifica- tion of more severe clinicopathological features. Surprisingly, however, we found that DPLN patients with 10$25 \%$ crescents in some aspects had more severe features than those with $\geq 50 \%$ crescents in glomeruli. Patients in this group had the longest SLE duration, highest age, and highest disease-onset age in our study. The prevalence of CRF, malignant hypertension, and TTP/HUS was markedly higher than in all other groups. Furthermore, they had the most severe glomerular sclerosis, acute tubulointerstitial lesions, vascular lesions, most prominent interstitial CD4+ infiltration, and the highest degree of microscopic hematuria. On one hand, this group of patients may not present with acute onset, rapid progression, and severe symptoms, and thus the diagnosis and treatment may be delayed. On the other hand, although both cellular and humoral immunity are suppressed in patients with renal insufficiency, we accordingly speculate that the degree of immune suppression may not be perfectly associated with the degree of renal damage. In addition, tubulointerstitial and vascular lesions were quite prominent in this group, which played a pivotal role in the development and prognosis of LN. In clinical work, much emphasis should be placed on this group of patients, and a specific mechanism remains to be further studied in the future.

Although there are no well-established guidelines for the treatment of crescentic glomerulonephritis in patients with LN, most authors, including the ACR/EULAR guidelines, recommend intensive immunosuppressive therapy on the therapeutic basis of proliferative LN [6, 33]. Our study demonstrated that the degree of histological crescents will have implications on treatment response and renal function deterioration in DPLN owing to severe clinical manifestations, serious pathological changes, and a higher AI and CI score. Therefore, we suggest that more aggressive treatment should be given to DPLN patients with histological crescents.

There were some limitations to this study. Firstly, this was a retrospective single-center study. Based on the patients' financial conditions and different physicians' clinical experiences, all patients were treated with a flexible strategy and without the exact unified medicines and duration. Secondly, there were difficulties in collecting and comparing previous medicines, treatment failures, and previous renal biopsy data before biopsy because many clinicopathological data were lost or incomplete. Thirdly, though we figured out that crescentic nephritis is most common in class IV LN, patients with class III, IV+III, and IV $+\mathrm{V}$ can also present with histological crescents under microscopy, but were excluded from this study. 
Therefore, a future well-designed prospective multicenter study is required to evaluate the long-term prognosis of LN patients with various degrees of histological crescents.

\section{Disclosure Statement}

The authors have no conflict of interest to declare.

\section{References}

-1 Tang Z, Yao X, Hu W, Zeng C, Chen H, Liu Z, Li L: The clinical and pathological characteristics of Chinese patients with pauci-immune crescent glomerulonephritis. Chin Med J 2001;114:374.

- Tang Z, Wu Y, Wang Q, Zeng C, Yao X, Hu W, Chen H, Liu Z, Li L: Clinical spectrum of diffuse crescentic glomerulonephritis in Chinese patients. Chin Med J 2003;116:1737.

> Chen $\mathrm{H}$, Tang Z, Zeng C, Hu W, Wang Q, Yu Y, Yao X, Wang J, Zhu M, Zhou H: Pathological demography of native patients in a nephrology center in China. Chin Med J 2003; 116:1377.

-4 Baqi N, Moazami S, Singh A, Ahmad H, Balachandra S, Tejani A: Lupus nephritis in children: a longitudinal study of prognostic factors and therapy. J Am Soc Nephrol 1996; 7:924-929.

-5 Leaker B, Fairley K, Dowling J, Kincaid-Smith P: Lupus nephritis: clinical and pathological correlation. Q J Med 1987;62:163-179.

6 Sumethkul V, Chalermsanyakorn P, Changsirikulchai S, Radinahamed P: Lupus nephritis: a challenging cause of rapidly progressive crescentic glomerulonephritis. Lupus 2000;9 424-428.

7 Cameron JS: Lupus nephritis. J Am Soc Nephrol 1999;10:413-424.

8 Tang Z, Wang Z, Zhang HT, Hu WX, Zeng $\mathrm{CH}$, Chen HP, Liu ZH, Li LS: Clinical features and renal outcome in lupus patients with diffuse crescentic glomerulonephritis. Rheumatol Int 2009;30:45-49.

-9 Yu F, Tan Y, Liu G, Wang SX, Zou WZ, Zhao $\mathrm{MH}$ : Clinicopathological characteristics and outcomes of patients with crescentic lupus nephritis. Kidney Int 2009;76:307-317.

$\checkmark 10$ Oudah N, Al Duhailib Z, Alsaad K, Qurashi S, Ghamdi G, Flaiw A, Hejaili F, Farooqui M, Al Sayyari A: Glomerulonephritis with crescents among adult Saudi patients outcome and its predictors. Clin Exp Med 2012;12:121-125.

11 Hochberg MC: Updating the American College of Rheumatology revised criteria for the classification of systemic lupus erythematosus. Arthritis Rheum 1997;40:1725-1725.
12 Weening JJ, D D’Agati V, Schwartz MM, Seshan SV, Alpers CE, Appel GB, Balow JE, Bruijn JA, Cook T, Ferrario F: The classification of glomerulonephritis in systemic lupus erythematosus revisited. Kidney Int 2004;65:521-530.

13 Austin H, Muenz LR, Joyce KM, Antonovych TT, Balow JE: Diffuse proliferative lupus nephritis: identification of specific pathologic features affecting renal outcome. Kidney Int 1984;25:689-695.

14 Solez K, Axelsen R, Benediktsson H, Burdick JF, Cohen AH, Colvin RB, Croker BP, Droz D, Dunnill MS, Halloran PF: International standardization of criteria for the histologic diagnosis of renal allograft rejection: the Banff working classification of kidney transplant pathology. Kidney Int 1993;44:411-411.

15 Chan T, Tse K, Tang CS, Lai K, Li F: Longterm outcome of patients with diffuse proliferative lupus nephritis treated with prednisolone and oral cyclophosphamide followed by azathioprine. Lupus 2005;14:265-272.

16 Korbet SM, Lewis EJ, Schwartz MM, Reichlin M, Evans J, Rohde RD: Factors predictive of outcome in severe lupus nephritis. Am J Kidney Dis 2000;35:904-914.

17 Mok CC, Ho CTK, Chan KW, Lau CS, Wong RWS: Outcome and prognostic indicators of diffuse proliferative lupus glomerulonephritis treated with sequential oral cyclophosphamide and azathioprine. Arthritis Rheum 2002;46:1003-1013.

-18 Liang MH, Socher SA, Larson MG, Schur PH: Reliability and validity of six systems for the clinical assessment of disease activity in systemic lupus erythematosus. Arthritis Rheum 1989;32:1107-1118.

19 Bombardier C, Gladman DD, Urowitz MB, Caron D, Chang CH, Austin A, Bell A, Bloch DA, Corey PN, Decker JL: Derivation of the SLEDAI. A disease activity index for lupus patients. Arthritis Rheum 1992;35:630-640.

20 Heaton JM, Turner D, Cameron J: Localization of glomerular 'deposits' in HenochSchönlein nephritis. Histopathology 1977;1: 93-104.

21 Schwartz MM, Roberts JL, Lewis EJ: Necrotizing glomerulitis of systemic lupus erythematosus. Hum Pathol 1983;14:158-167.

-22 Ferrario F, Napodano P, Giordano A, Gandini E, Boeri R, D’Amico G: Peculiar type of focal and segmental lupus glomerulitis: glomerulonephritis or vasculitis?; in Sessa A, Meroni M, Battini G: Systemic Lupus erythematosus: Renal Vasculitis. Contrib Nephrol. Basel, Karger, 1992, vol 99, p 86.
23 Najafi CC, Korbet SM, Lewis EJ, Schwartz MM, Reichlin M, Evans J: Significance of histologic patterns of glomerular injury upon long-term prognosis in severe lupus glomerulonephritis. Kidney Int 2001;59:2156-2163.

24 Hill GS, Delahousse M, Nochy D, Bariety J: Class IV-S versus class IV-G lupus nephritis: clinical and morphologic differences suggesting different pathogenesis. Kidney Int 2005; 68:2288-2297.

$\checkmark 25$ Mittal B, Hurwitz S, Rennke H, Singh AK: New subcategories of class IV lupus nephritis: are there clinical, histologic, and outcome differences. Am J Kidney Dis 2004;44:10501059

26 Schwartz MM, Korbet SM, Lewis EJ: The prognosis and pathogenesis of severe lupus glomerulonephritis. Nephrol Dial Transplant 2008;23:1298-1306.

-27 Schwartz M, Korbet S, Katz R, Lewis E: Evidence of concurrent immunopathological mechanisms determining the pathology of severe lupus nephritis. Lupus 2009;18:149-158.

28 Behara VY, Whittier WL, Korbet SM, Schwartz MM, Martens M, Lewis EJ: Pathogenetic features of severe segmental lupus nephritis. Nephrol Dial Transplant 2010;25: 153-159.

29 Tarzi RM, Cook HT, Pusey CD: Crescentic glomerulonephritis: new aspects of pathogenesis: Semin Nephrol 2011;31:361-368.

- 30 Tang Z, Wu Y, Hu W, Yao X, Zhou H, Chen $\mathrm{H}$, Liu Z, Li L: The distribution and significance of renal infiltrating cells in patients with diffuse crescentic glomerulonephritis. Chin Med J 2001;114:1267.

-31 Tipping PG, Holdsworth SR: T cells in crescentic glomerulonephritis. J Am Soc Nephrol 2006;17:1253-1263.

32 Singh SK, Jeansson M, Quaggin SE: New insights into the pathogenesis of cellular crescents. Curr Opin Nephrol Hypertens 2011;20: 258

33 Nasr SH, D’Agati VD, Park H-R, Sterman PL, Goyzueta JD, Dressler RM, Hazlett SM, Pursell RN, Caputo C, Markowitz GS: Necrotizing and crescentic lupus nephritis with antineutrophil cytoplasmic antibody seropositivity. Clin J Am Soc Nephrol 2008;3:682-690. 